\title{
Successful Wildlife Conservation Requires Good Governance
}

\author{
Emily F. Pomeranz ${ }^{1 *}$, Darragh Hare ${ }^{2,3}$, Daniel J. Decker ${ }^{3}$, Ann B. Forstchen ${ }^{4}$, \\ Cynthia A. Jacobson ${ }^{5}$, Christian A. Smith ${ }^{6}$ and Michael V. Schiavone ${ }^{7}$
}

${ }^{1}$ Michigan Department of Natural Resources, Lansing, MI, United States, ${ }^{2}$ Wildlife Conservation Research Unit, Department of Zoology, University of Oxford, Oxford, United Kingdom, ${ }^{3}$ Center for Conservation Social Sciences, Cornell University, Ithaca, NY, United States, ${ }^{4}$ Florida Fish and Wildlife Conservation Commission, St. Petersburg, FL, United States, ${ }^{5}$ Innovative Outcomes, Carbondale, CO, United States, ${ }^{6}$ Wildlife Management Institute, Helena, MT, United States, ${ }^{7}$ New York State Department of Environmental Conservation, Albany, NY, United States

\section{OPEN ACCESS}

Edited by:

Dhananjaya Katju,

American University, United States

Reviewed by:

Edwin Muchapondwa,

University of Cape Town, South Africa

Jessica Bell Rizzolo,

Michigan State University,

United States

*Correspondence:

Emily F. Pomeranz

pomeranze@michigan.gov

Specialty section

This article was submitted to

Human-Wildlife Dynamics,

a section of the journal

Frontiers in Conservation Science

Received: 04 August 2021 Accepted: 20 September 2021

Published: 14 October 2021

Citation:

Pomeranz EF, Hare D, Decker DJ,

Forstchen $A B$, Jacobson $C A$

Smith CA and Schiavone MV (2021)

Successful Wildlife Conservation

Requires Good Governance.

Front. Conserv. Sci. 2:753289.

doi: 10.3389/fcosc.2021.753289
Public wildlife management in the United States is transforming as agencies seek relevancy to broader constituencies. State agencies in the United States, while tasked with conserving wildlife for all beneficiaries of the wildlife trust, have tended to manage for a limited range of benefits in part due to a narrow funding model heavily dependent on hunting, fishing, and trapping license buyers. To best meet the needs, interests, and concerns of a broader suite of beneficiaries, agencies will need to reconsider how priorities for management are set. This presents an opportunity for conservation program design and evaluation to be elevated in importance. We argue that success in wildlife conservation in the U.S. requires assessment of both decision-making processes and management results in relation to four questions: conservation of what, under what authority, for what purposes, and for whom?

Keywords: wildlife conservation, wildlife management, program evaluation, public trust, good governance, relevancy

\section{INTRODUCTION}

Public Wildlife Management in the United States (U.S.) is transforming, illustrated by growing momentum among wildlife agencies to foster conservation relevancy across broader segments of society (Association of Fish Wildlife Agencies The Wildlife Management Institute, 2019; Manfredo et al., 2020; Metcalf et al., 2020, Jacobson et al. in review). This presents an opportunity for program evaluation in wildlife conservation to be elevated in importance. Prerequisites for evaluating success of a wildlife conservation program are an explicit intended outcome and a timeline for accomplishing it. In addition, reliability and validity of evaluation metrics and quality of methods used to measure program accomplishments must meet scientific and professional standards. While clearly articulated program objectives and valid measurements are essential for effective evaluation, they alone are inadequate to evaluate success. One must also consider the process used to decide on program objectives and methods, the substance of intended outcomes, and the appropriateness of evaluation criteria. If the process used to determine objectives or methods is arbitrary or opaque, public acceptance (a metric of success for any public resource decision) may be low. While achievement of program objectives is critical for evaluating conservation success, the process for determining those objectives must be grounded in good governance, else the outcomes may be misplaced, misguided, or irrelevant to the beneficiaries conservation is intended to serve. Indeed, the more effectively a program pursues the "wrong" outcomes, the farther the end result will be from success, despite achieving intended objectives. This situation can be avoided if attention to program evaluation starts when conservation goals and objectives are formulated. 
To be considered successful, wildlife conservation must achieve the "right" outcomes. This raises two fundamental questions:

1. How can managers ensure conservation programs target the right outcomes?

2. How will managers know whether or not they have achieved the right outcomes?

Answers to these questions will differ across legal, political, and governance systems, depending, for example, on whether ownership of wildlife is vested in government, transferred to local communities, or tied to private land ownership (FAO., 2002; Aggarwal and Elbow, 2006; Kamal et al., 2015). Based on our experience working within the conservation institution in the U.S., where primary responsibility for wildlife conservation rests with state governments (Freyfogle and Goble, 2009), appropriate intended outcomes for conservation can be established through processes grounded in wildlife governance principles reflecting comprehensive public trust thinking and good governance norms (Jacobson et al., 2010; Decker et al., 2016).

As social values toward wildlife in the U.S. move away from traditional, utilitarian ways of valuing wildlife toward a more mutualistic orientation, the work of wildlife conservation agencies becomes more complex, as demonstrating inclusivity toward a range of beneficiary interest complicates the management context (Decker et al., 2016; Manfredo et al., 2017 , 2018). Traditional approaches to top-down management are no longer are sufficient to address this complex context; now, the core work of conservation professionals is considering who should be involved in decision-making processes and how those processes should be developed, i.e., governance (Armitage et al., 2012). Good governance provides "normative guidance" for these processes (Pomeranz and Stedman, 2020, p. 429). Principles of good governance have been articulated in a variety of contexts, including natural resources, yet often involving some variation on core concepts such as accountability, efficiency, transparency, legitimacy, and inclusivity (Lockwood, 2010; Lockwood et al., 2010; van Doeveren, 2011; Pomeranz and Stedman, 2020).

Uniting principles of good governance and public trust thinking (Lockwood, 2010; Hare and Blossey, 2014), Decker et al. (2016) proposed 10 wildlife governance principles which assert that public wildlife governance will be adaptable and responsive to public needs and interests, incorporating multiple diverse perspectives and applying social and ecological science to produce multiple, sustainable benefits for current and future members of the public. Furthermore, they assert that wildlife governance is accessible and transparent, allowing members of the public to fully participate and hold trust administrators accountable.

Building on the work of Decker et al. (2016), in this paper we argue that success in wildlife conservation in the U.S. requires trustees, trust managers and citizen beneficiaries (as described by Smith, 2011) to play their roles in decision-making processes that define desired program objectives and acceptable management methods (Figure 1). To evaluate success of wildlife conservation in this context requires assessment of decision-making processes and outcomes in relation to four questions: conservation of what, under what authority, for what purposes, and for whom?

\section{CONSERVATION OF WHAT? PUBLIC WILDLIFE RESOURCES}

State governments define terms such as "wildlife" and "wildlife resources" in multiple ways (Blumm and Paulsen, 2013; Metcalf et al., 2020). The scope of legal responsibility of state wildlife agencies (SWAs) is similarly variable (Freyfogle and Goble, 2009), with some responsible for a relatively narrow range of species, typically focused on those pursued by hunters and anglers (e.g., Pennsylvania Const. Stat $34 \S 103$ which defines state ownership of wildlife as game species only), and others with broad mandates (e.g., Idaho Code $36 \S 103$ which declares "all wild animals, wild birds, and fish" to be property of the state). Regardless of the specific legal obligations of a SWA, we assume that to fulfill its public trust responsibilities any SWA must be cognizant of, and attentive to, the full range of wild living resources within its geopolitical jurisdiction. Some SWAs have expressed an expansive aspiration, adopting a mission of conserving all wildlife for all people (e.g., Florida Fish and Wildlife Conservation Commission's mission of “managing fish and wildlife resources for their long-term well-being and the benefit of people") (Decker et al., 2012a,b).

\section{UNDER WHAT AUTHORITY? PUBLIC TRUST DOCTRINE}

In most U.S. states, wildlife is treated in law as a public trust resource (Horner, 2000; Freyfogle and Goble, 2009). This status is rooted in case law (e.g., federal Supreme Court decisions) collectively known as the public trust doctrine (Sax, 1970; Blumm and Paulsen, 2013), which establishes that wildlife in the U.S. is public property, held in trust by (committed into care of) government (Bean and Rowland, 1997). Trust management includes regulating specific uses of wildlife and managing wildlife generally for the benefit of current and future generations. Variability in interpretation of the public trust concept in the U.S. has resulted in multiple versions of it in common law, statutory law, and state constitutions (Horner, 2000; Redmond, 2009). Whatever particular form the public trust mandate takes in a specific state jurisdiction, it provides the foundation for governance of public wildlife resources (Geist and Organ, 2004; Organ and Batcheller, 2009; Smith, 2011; Hare et al., 2017; Treves et al., 2017). Essentially, SWAs are expected to carry out their responsibilities by managing wildlife for the benefit of the public. In spirit, if not in practice, this means all members of the public.

\section{FOR WHAT PURPOSE? BENEFITS}

Wildlife agencies exist to ensure that wildlife provides sustainable net positive value (benefits) for current and future generations. Although the nature of human-wildlife interactions and the many kinds of impacts they produce are diverse, benefits of wildlife management can be thought of broadly as outcomes 


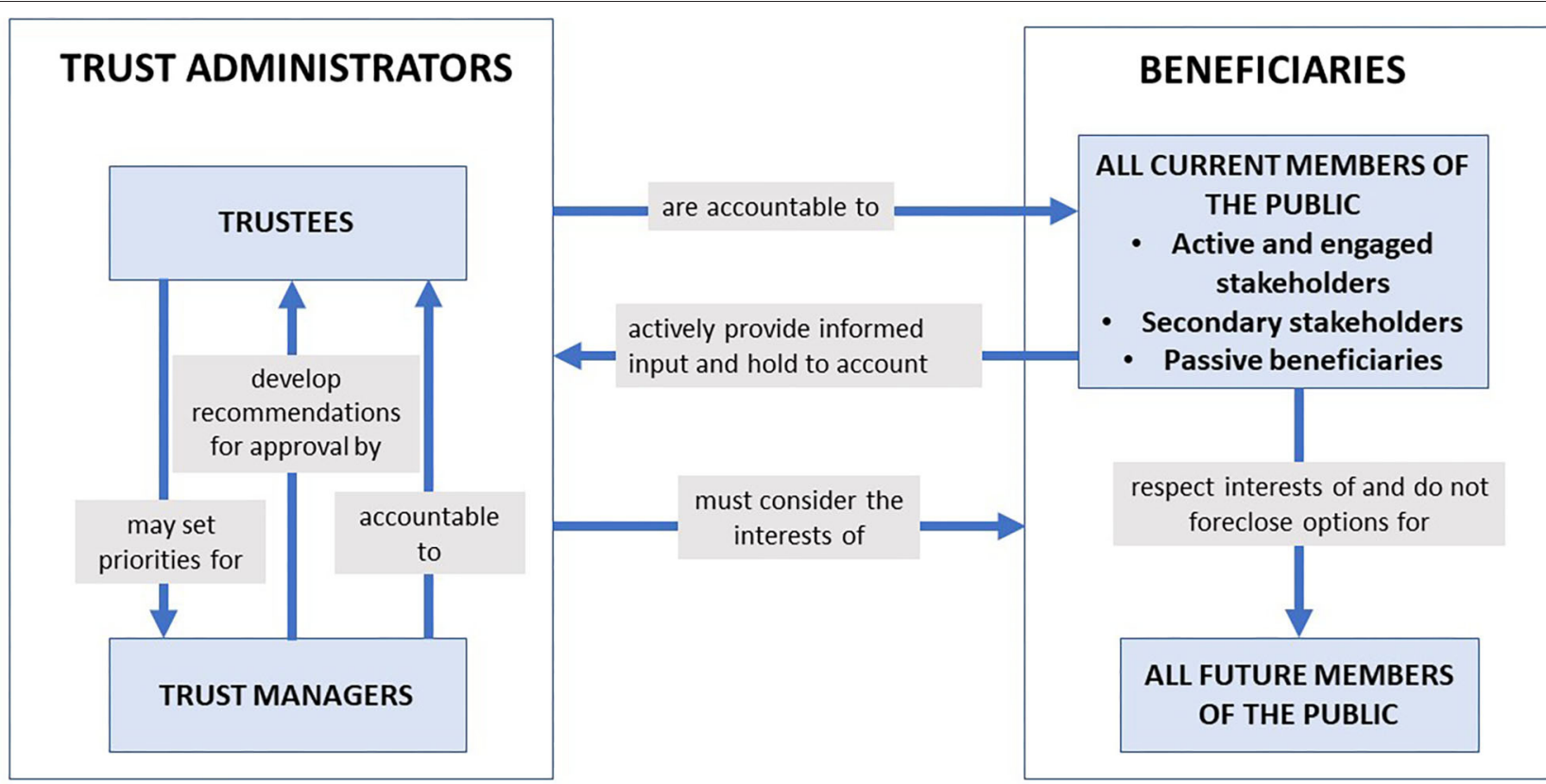

FIGURE 1 | Relationships between categories of actors in public wildlife governance in the United States. Public wildlife trust administrators comprise trustees (elected and appointed officials) and trust managers (various types of professionals employed by public wildife agencies). Beneficiaries comprise all current and future members of the public. Current beneficiaries hold trust administrators accountable in many direct and indirect ways. Beneficiaries have an obligation to be active, adequately informed participants in decision making. Beneficiaries and trust administrators must consider the interests of future generations and avoid foreclosing options for future wildlife resource interests.

that promote public well-being (healthy, happy people; healthy ecosystems; etc.), and for some people includes the idea that wildlife has value for its own sake, beyond its contribution to people's well-being. Wildlife management benefits include reducing negative outcomes or costs associated with wildlife (e.g., economic loss to agriculture, property damage, health and safety risks) as well as increasing a variety of positive outcomes produced by management of wildlife (e.g., viewing enjoyment, recreation, food, cultural significance).

Some may assume that successfully managing wildlife as a trust asset means maintaining or growing the number of animals in a population (regardless of whether it is considered too many or few by stakeholders). That would be a narrow view of trust administration effectiveness given the range of public needs, interests, and concerns (NICs). Some minimal level of a wildlife population is required for conservation, but high numbers of animals may not be necessary for all types of benefits to be experienced or enhanced, or for populations of a species to be sustainable. Numbers of animals well below what is biologically possible may be adequate or even optimal for the greatest net benefit for multiple public NICs in a particular geographic area. Interests of some people may be harmed by larger populations of some species of wildlife. Thus, maximizing numbers alone could be counterproductive to optimizing net benefits for society. A more robust way to view the public wildlife trust is as an obligation to manage for a suite of positive outcomes made possible by wildlife, which inherently includes the requirement to conserve populations and species.
The presence of wildlife is necessary but not always sufficient to produce desired benefits. Wildlife must exist for net benefits to result, and population sizes can be a useful metric to assess the status of trust assets. However, an exclusive focus on wildlife population numbers is inadequate for wildlife management that aspires to be responsive to NICs of diverse members of the public who expect trust administration to produce a variety of benefits. Trust administration seeks to increase the kinds and quantity of wildlife-associated benefits, not just the number of wild organisms.

\section{FOR WHOM? STAKEHOLDERS TO BENEFICIARIES}

Thinking over the last 30 years has evolved regarding whose NICs public wildlife management should serve. The historical focus on people who purchase hunting, fishing, or trapping licenses and those who control private land providing habitat for game species (farmers, forest landowners, etc.) expanded to stakeholders (Decker et al., 1996) during the latter years of the 20th century and more recently to beneficiaries (Decker et al., 2019). Stakeholders are a subset of beneficiaries who significantly affect or are significantly affected by wildlife or wildlife management (Decker et al., 2012b). The concept of beneficiaries is more inclusive and is consistent with the public trust nature of wildlife resources. If we think about beneficiaries as being all members of the public (Hare and Blossey, 2014), arguably the U.S. population 
can be segmented into three broad categories with respect to benefits received from wildlife management: people whom public wildlife management has historically well-served, underserved, and never intentionally served.

State agencies have come to recognize the need to increase their relevancy to more segments of society for philosophical, legal and practical reasons (Kellert et al., 2017; Kondo et al., 2018; Manfredo et al., 2018, Jacobson et al. in review), making their answer to the question "for whom do we manage wildlife?" critical. To varying extents SWAs are aware of their public trust obligations to conserve all species for all members of the public. Ideally SWAs would add to their portfolios a broad range of programs and services that address the NICs of previously underserved and never-served segments of the American population (Hare et al., 2017). This thinking will help agencies meet legal and social expectations for diversity, equity, and inclusion considerations in their programs. Most SWAs need support beyond their historic funding model, which is dependent on a limited-and in many states declining-segment of the beneficiary population: hunters and trappers (Duda et al., 2021). It is unrealistic to think that the public (and therefore political) support necessary to diversify and expand funding for SWAs will materialize without first demonstrating the current and potential future value of wildlife management programs to more and more diverse beneficiaries. Recognizing this, in 2019, the directors of SWAs, acting through the Association of Fish and Wildlife Agencies, endorsed the Fish and Wildlife Relevancy Roadmap as a practical guide for states to reference in pursuit of engaging and serving broader segments of American society-including those underserved and never served by conservation (Association of Fish Wildlife Agencies The Wildlife Management Institute, 2019).

\section{ADMINISTRATION OF THE TRUST AND PEOPLE'S RELATED NICS}

Wildlife-resource trustees (elected officials and their appointees), wildlife managers and beneficiaries of wildlife management all need to be aware of the suite of outcomes the trust is capable of producing if desired benefits are to flow from management. If members of the public are not aware of benefits they might experience from wildlife management, and only a subset of benefits are the focus of management (intentionally or unintentionally), then a wildlife program achieving the prescribed set of benefits may appear successful by virtue of the self-limiting nature of its aspirations. Nonetheless, it is perhaps falling well short of the potential for producing benefits for more people. Concomitantly, all parties need to be cognizant of the potential outcomes desired by the entire set of beneficiaries if wildlife resources are to be administered transparently, fairly, and successfully for all people to whom trustees are legally accountable. If all potential beneficiaries do not know what benefits wildlife management can produce, then something is amiss, diminishing the success of a program. Furthermore, those actively engaged in the trust as administrators or beneficiaries need to be mindful that benefits desired may change over time and across generations, requiring current trust administrators to make decisions that maintain options for the future.

Trustees require insights from beneficiaries about what they believe constitute desirable benefits from wildlife. In public wildlife management, beneficiaries therefore have a significant role in defining the benefits expected and in decision making about program objectives and actions that are designed to yield such benefits (Forstchen and Smith, 2014; Decker et al., 2015). This means all members of the public, for whom a common right of access exists and whose interests trustees must consider, have the obligation and the opportunity to communicate the benefits they seek from management. Beneficiaries should expect that their desires are considered by trustees and trust managers in the production and allocation of benefits from wildlife management. Furthermore, residents throughout a jurisdiction (e.g., state), not just those living proximal to particular wildlife assets, are legitimate sources of input for wildlife management decision making. It follows that involvement of diverse beneficiaries is paramount when setting objectives for wildlife-benefits management, for example through systematic inquiry or robust public engagement processes, to understand beneficiaries' NICs. No public wildlife program can be considered successful if its objectives are not arrived at via an inclusive decisionmaking process. Such a process involves comprehensive trade-off analysis yielding the greatest net benefits for society given the constraints of a particular situation. This is vital to sound wildlife trust administration and therefore to any notion of wildlife program success.

\section{IMPLICATIONS FOR WHAT CONSTITUTES "SUCCESS"}

The fundamental importance of public trust thinking (Hare and Blossey, 2014) to U.S. wildlife governance has profound implications for evaluating success of wildlife management. The tenets of good governance are obligatory criteria for wildlife conservation success (Lockwood et al., 2010). Arguably, the better aligned a wildlife management program's decision making process is to the attributes of public trust thinking and good governance listed in Figure 2 (Decker et al., 2016), the more successful that program may be considered.

Ensuring SWA staff have an understanding and acceptance of public trust thinking, good governance (Lockwood et al., 2010; Decker et al., 2016) and their and others' roles in naturalresource trust administration (Smith, 2011) is critical to broaden thinking about for whom wildlife are managed and why, and to ensure the design and implementation of effective conservation. Several assessment tools exist to assist SWAs in determining their readiness and performance with respect to wildlife governance principles (Decker et al., 2016; Hare et al., 2017). Results from the assessment tools encourage discussion about the conditions that exist in a particular governance context, particularly traits and practices that have been identified as aiding or impeding application of wildlife governance principles. Such assessments aid SWAs work to evaluate their conservation effectiveness. An agency may not always completely align with all 10 principles 


\section{A wildlife management program can be considered successful if it meets the following criteria:}

1. is responsive to citizens' current needs, interests and concerns (NICs), while also being forward-looking to conserve options of future generations (i.e., decision making should respond to present interests without precluding future needs).

2. seeks and incorporates multiple, diverse perspectives, including ethical perspectives.

a. Wildlife resources are managed with consideration given to all citizens' NICs, not exclusively to the interests of narrowly-focused or vocal stakeholders.

b. Program objectives have been scrutinized to avoid built-in biases or omission of possibilities.

3. is led using well-informed, sound judgment by administrators (e.g., commissioners, directors, and wildlife professionals) in decisions about allocation of benefits produced by wildlife resources being managed, with potential collateral and subsequent effects identified.

4. provides myriad sustainable ecological, aesthetic, economic and recreational benefits, allocated equitably (without systematically privileging some beneficiaries over others).

5. is efficient, effective, and adaptive.

6. is publicly accessible and transparent, reflecting a mutually respectful and productive relationship between beneficiaries and trust administrators, from setting objectives to implementing actions.

7. employs appropriate and accessible mechanisms that allow beneficiaries to hold trust administrators accountable.

8. includes means for citizens to become adequately informed and productively engaged in decision making.

9. includes opportunities for beneficial partnerships that magnify or extend program impact (benefits produced).

10. facilitates collaboration and coordination across ecological, jurisdictional and ownership boundaries.

FIGURE 2 | Ten standards for success in wildlife governance in the United States. These standards can help public wildlife managers define, measure, and evaluate success of particular policies and programs. Each standard correlates with one of the ten wildlife governance principles presented by Decker et al. (2016).

for every conservation program. Failure to achieve a principle does not mean a program should be dismissed outright, but instead presents an opportunity for learning and improvement. Understanding where an agency does or does not align with wildlife governance principles gives focus for self-reflection and discussion of opportunities to enhances agency function and achievement of positive conservation outcomes.

Adherence to the 10 wildlife governance principles has implications for who should be involved in evaluation efforts. While elected or appointed officials have primary decisionmaking authority for public trust wildlife resources, wildlife professionals working in SWAs also have important roles, including monitoring and managing the corpus of the trust (wildlife and habitat) to attain the goals set by the trustees on behalf of beneficiaries, and distribute benefits that derive from those goals (Figure 1). Critically, diverse beneficiary involvement is necessary to ensure a full range of potential benefits is identified by them or communicated to them, and to ensure that actions selected to achieve desired outcomes align with their ethical perspectives. Programs that focus on a narrow set of benefits fail to meet their public trust responsibilities, which can be alleviated by more inclusive public engagement. The literature on public conservation programs in the U.S. is replete with examples of wildlife decision-making processes that have suffered critique from stakeholders for either the dearth or the quality of their engagement efforts, underscoring how critical sound engagement is to achieving principles of wildlife governance. For example, examining a participatory approach to deer management decision making in New York State, Pomeranz and Decker (2018) found that, "according to the perception of most participants and the state wildlife agency conveners, both the process and outcome... were flawed. At the root, lack of diversity of participants pervaded dissatisfaction with both process and outcome" (p. 412). Examining decision making around an elk hunt in Grand Teton National Park, Wyoming, Vernon and Clark (2016) found that those opposed to the elk hunt said that "current management arrangements denied them meaningful involvement, demanding inclusion in decision making" (p. 845). Vernon and Clark (2016) contend that conflict could be more effectively addressed by "a more respectful and inclusive social and decision-making process" (p. 848).

Engaging beneficiaries is important to ensure that the metrics and means used in program evaluation are considered both important and credible to beneficiaries, the people to whom trust administrators are ultimately accountable. Partners should be involved in evaluation as well because they typically provide some type of resource or capital for programs and expect evidence to gauge the impact of their investments.

Wildlife program evaluation starts with critical review of the program plan, with an emphasis on objectives and methods. This pre-implementation checklist can help make sure the program has potential for success: 
1. Clearly articulated purpose statement about what the program is trying to achieve, both in terms of conservation outcomes and good governance-necessary for overall program evaluation.

2. Decision-making process includes partners and beneficiaries (known stakeholders and other members of the public), as well as trustee/trust manager decision makers.

3. Objectives optimize benefits produced and are achievable (nature, extent, and timing for outcomes are clear)—necessary for outcomes evaluation.

4. Program design adequacy-the necessary elements are included in the program design with proper sequencing and timing.

5. Program implementation adequacy - the necessary resources (partnerships, money, human capital, political support, etc.) are available and committed to the program.

6. Potential collateral and subsequent effects of program activity have been identified and plans are in place to avoid, minimize, or mitigate the most egregious effects anticipated.

Although our focus is on the conservation institution in the U.S., this checklist may be useful to resource managers in other jurisdictions, especially those where public ownership of wildlife, public trusteeship, and expectations of good governance exist (Sagarin and Turnipseed, 2012; Hare et al., 2018; Giacomelli et al., 2019). We anticipate that our more general pointthat wildlife conservation must pursue the "right" objectivesmight also apply in jurisdictions with alternative legal and institutional arrangements.

\section{CONCLUSION}

Applying principles of wildlife governance, and subsequently engaging in evaluation of adherence to those principles while developing program objectives, will not be without challenges. As Hare et al. (2017) note, applying principles based in

\section{REFERENCES}

Aggarwal, S., and Elbow, K. (2006). The Role of Property Rights in Natural Resource Management, Good Governance and Empowerment of the Rural Poor. Washington, DC: United States Agency for International Development.

Armitage, D., De Loë, R., and Plummer, R. (2012). Environmental governance and its implications for conservation practice. Conserv. Lett. 5, 245-255. doi: $10.1111 / j .1755-263 X .2012 .00238 . x$

Association of Fish and Wildlife Agencies and The Wildlife Management Institute (2019). Fish and Wildlife Relevancy Roadmap: Enhanced Conservation Through Broader Engagement (v1.0), eds M. Dunfee, A. Forstchen, E. Haubold, M. Humpert, J. Newmark, J. Sumners, and C. Smith (Washington, DC: AFWA), 128.

Bean, M. J., and Rowland, M. J. (1997). The Evolution of National Wildlife Law. Westport, CT: Praeger. doi: 10.2307/39 85338

Bennett, N. J., Di Franco, A., Calò, A., Nethery, E., Niccolini, F., Milazzo, M., et al. (2019). Local support for conservation is associated with perceptions of good governance, social impacts, and ecological effectiveness. Conserv. Lett. 12:e12640. doi: 10.1111/conl. 12640 sound public trust thinking "will only be achieved through committed collaboration and cooperation... supported and legitimized by diverse beneficiaries engaged throughout decisionmaking processes" (p. 519). Good governance more broadly is rarely achieved in its idealized forms, resulting in what Grindle (2004) calls "good enough" governance (Bernstein, 2005). There are also few examples of evaluation of good governance in wildlife management (see Turner et al., 2014; Bennett et al., 2019; Pomeranz and Stedman, 2020 for a few of the limited examples). Developing a culture of formative and summative evaluation within state wildlife agencies in the U.S. will take commitment, and for many, striving to achieve the principles of wildlife governance may be, in part, aspirational.

As public wildlife management in the U.S. strives to enhance its relevancy among a greater share of society, critical evaluation of conservation programs should become a key practice of SWAs. Adopting the evaluation perspective described in this article as a primary activity of SWAs pursuing relevancy goals can help ensure that the basic principles of good wildlife governance are being incorporated into the thinking and actions of wildlife trust administrators and others. The outcomes for current and future generations of both people and wildlife have potential to be positive and long-lasting if evaluation enhances adherence to these principles.

\section{DATA AVAILABILITY STATEMENT}

The original contributions presented in the study are included in the article/supplementary material, further inquiries can be directed to the corresponding author.

\section{AUTHOR CONTRIBUTIONS}

All authors contributed to manuscript development, writing, revision, read, and approved the submitted version.

Bernstein, S. (2005). Globalization and the requirements of "good" environmental governance. Perspect. Global Dev. Technol. 4, 645-679. doi: $10.1163 / 156915005775093278$

Blumm, M., and Paulsen, A. (2013). The public trust in law review. Utah Law Rev. 6. doi: $10.2139 /$ ssrn. 2189134

Decker, D., Smith, C., Forstchen, A., Hare, D., Pomeranz, E., Doyle-Capitman, C., et al. (2016). Governance principles for wildlife conservation in the 21st century. Conserv. Lett. 9, 290-295. doi: 10.1111/conl.12211

Decker, D. J., Forstchen, A., Siemer, W., Smith, C., Frohlich, R. K., Schiavone, M., et al. (2019). Moving the paradigm from stakeholders to beneficiaries in wildlife management. J. Wildl. Manage. 83, 513-518. doi: 10.1002/jwmg. 21625

Decker, D. J., Forstchen, A. B., LeClaire-Mitchell, A. M., and Jacobson, C. A. (2012a). "Seeking common ground for collaborative conservation: Overcoming barriers and building bridges to a wildlife conservation institution for "all wildlife for all people", in Transactions of the 76th North American Wildlife and Natural Resources Conference (Milwaukee, WI).

Decker, D. J., Forstchen, A. B., Pomeranz, E. F., Smith, C. A., Riley, S. J., Jacobson, C. A., et al. (2015). Stakeholder engagement in wildlife management: does the public trust doctrine imply limits? J. Wildl. Manage. 79, 174-179. doi: 10.1002/jwmg.809 
Decker, D. J., Krueger, C. C., Baer, J.r.,. R. A., Knuth, B. A., and Richmond, M.E. (1996). From clients to stakeholders: a philosophical shift for fish and wildlife management. Hum. Dimens. Wildl. 1, 70-82. doi: 10.1080/10871209609359053

Decker, D. J., Riley, S. J., and Siemer, W. F. (2012b). Human Dimensions of Wildlife Management, 2nd Edn. Baltimore, MD: Johns Hopkins University Press.

Duda, M. D., Beppler, T., Austen, D. J., and Organ, J. F. (2021). The precarious position of wildlife conservation funding in the United States. Hum. Dimens. Wildl. 1-9. doi: 10.1080/10871209.2021.1904307

FAO. (2002). Legal Trends in Wildlife Management. Rome: Food and Agriculture Organization of the United Nations.

Forstchen, A. B., and Smith, C. A. (2014). The essential role of human dimensions and stakeholder participation in states' fulfilment of public trust responsibilities. Hum. Dimens. Wildl. 19, 417-426. doi: 10.1080/10871209.2014.940561

Freyfogle, E. T., and Goble, D. D. (2009). Wildlife Law: A Primer. Washington, DC: Island Press.

Geist, V., and Organ, J. F. (2004). The public trust foundation of the North American model of wildlife conservation. Trans. Northeast Sec. Wildl. Soc. $58,49-56$.

Giacomelli, S., Hare, D., Blossey, B., and Gibbert, M. (2019). Public trust thinking and public ownership of wildlife in Italy and the United States. Environ. Policy Governance 29, 209-219. doi: 10.1002/eet.1848

Grindle, M. S. (2004). Good enough governance: poverty reduction and reform in developing countries. Governance 17, 525-548. doi: 10.1111/j.0952-1895.2004.00256.x

Hare, D., and Blossey, B. (2014). Principles of public trust thinking. Hum. Dimens. Wildl. 19, 397-406. doi: 10.1080/10871209.2014.942759

Hare, D., Decker, D. J., Smith, C. A., Forstchen, A. B., and Jacobson, C. A. (2017). Applying public trust thinking to wildlife governance in the United States: challenges and potential solutions. Hum. Dimens. Wildl. 22, 506-523. doi: 10.1080/10871209.2017.1359864

Hare, D., Smith, C. A., Forstchen, A. B., and Decker, D. J. (2018). Developing governance principles for public natural resources. Soc. Nat. Resour. 31, 382-388. doi: 10.1080/08941920.2017.1400627

Horner, S. (2000). Embryo, not fossil: breathing life into the public trust in wildlife. Land Water Law Rev. 35, 23-75.

Jacobson, C. A., Organ, J. F., Decker, D. J., Batcheller, G. R., and Carpenter, L. (2010). A conservation institution for the 21st century: Implications for state wildlife agencies. J. Wildl. Manage. 74, 203-209. doi: 10.2193/2008-485

Kamal, S., Grodzińska-Jurczak, M., and Brown, G. (2015). Conservation on private land: a review of global strategies with a proposed classification system. J. Environ. Plan. Manage. 58, 576-597. doi: 10.1080/09640568.2013.875463

Kellert, S. R., Case, D. J., Escher, D., Witter, D. J., Mikels-Carrasco, J., and Seng, P. T. (2017). The nature of Americans: disconnection and recommendations for reconnection. National Report. Available online at: www.natureofamericans.org (accessed February 09, 2020)

Kondo, M. C., Fluehr, J. M., McKeon, T., and Branas, C. C. (2018). Urban green space and its impact on human health. Int. J. Environ. Res. Public Health 15:445. doi: 10.3390/ijerph15030445

Lockwood, M. (2010). Good governance for terrestrial protected areas: a framework, principles and performance outcomes. J. Environ. Manage. 91, 754-766. doi: 10.1016/j.jenvman.2009.10.005

Lockwood, M., Davidson, J., Curtis, A., Stratford, E., and Griffith, R. (2010). Governance principles for natural resources management. Soc. Nat. Resour. 23, 986-1001. doi: 10.1080/08941920802178214

Manfredo, M. J., Sullivan, L., Don Carlos, A. W., Dietsch, A. M., Teel, T. L., Bright, A. D., et al. (2018). America's Wildlife Values: The Social Context of Wildlife Management in the U.S. National report from the research project entitled "America's Wildlife Values." Fort Collins, CO: Colorado State University, Department of Human Dimensions of Natural Resources.

Manfredo, M. J., Teel, T. L., Don Carlos, A. W., Sullivan, L., Bright, A. D., Dietsch, A. M., et al. (2020). The changing sociocultural context of wildlife conservation. Conserv. Biol. 34, 1549-1559. doi: 10.1111/cobi. 13493

Manfredo, M. J., Teel, T. L., Sullivan, L., and Dietsch, A. M. (2017). Values, trust, and cultural backlash in conservation governance: the case of wildlife management in the United States. Biol. Conserv. 214, 303-311. doi: 10.1016/j.biocon.2017.07.032

Metcalf, J. D., Karns, G. R., Gade, M. R., Gould, P. R., and Bruskotter, J. T. (2020). Agency mission statements provide insight into the purpose and practice of conservation. Hum. Dimens. Wildl. 26, 262-274. doi: 10.1080/10871209.2020.1817630

Organ, J. F., and Batcheller, G. R. (2009). "Reviving the public trust doctrine as a foundation for wildlife management in North America," in Wildlife and Society: The Science of Human Dimensions, eds M. J. Manfredo, J. J. Vaske, P. J. Brown, D. J. Decker, and E. A. Duke (Washington, DC: Island Press), 161-171.

Pomeranz, E. F., and Decker, D. J. (2018). Designing regional-level stakeholder engagement processes: striving for good governance while meeting the challenges of scale. J. Environ. Policy Plan. 20, 403-418. doi: 10.1080/1523908X.2017.1417119

Pomeranz, E. F., and Stedman, R. C. (2020). Measuring good governance: piloting an instrument for evaluating good governance principles. J. Environ. Policy Plan. 22, 428-440. doi: 10.1080/1523908X.2020.1753181

Redmond (2009). Public trust in wildlife: two steps forward, two steps back. Nat. Resour. J. 49:249. doi: 10.2144/000113505

Sagarin, R. D., and Turnipseed, M. (2012). The public trust doctrine: where ecology meets natural resources management. Annu. Rev. Environ. Resour. 37, 473-496. doi: 10.1146/annurev-environ-031411-165249

Sax, J. L. (1970). The public trust doctrine in natural law: effective judicial intervention. Michigan Law Rev. 68, 471-566. doi: 10.2307/1287556

Smith, C. A. (2011). The role of state wildlife professionals under the public trust doctrine. J. Wildl. Manage. 75, 1539-1643. doi: 10.1002/jwmg.202

Treves, A., Chapron, G., López-Bao, J. V., Shoemaker, C., Goeckner, A. O., and Bruskotter, J. (2017). Predators and the public trust. Biol. Rev. 92, 248-270. doi: $10.1111 /$ brv.12227

Turner, R. A., Fitzsimmons, C., Forster, J., Mahon, R., Peterson, A., and Stead, S. M. (2014). Measuring good governance for complex ecosystems: perceptions of coral reef-dependent communities in the Caribbean. Global Environ. Change 29, 105-117. doi: 10.1016/j.gloenvcha.2014.08.004

van Doeveren, V. (2011). Rethinking good governance: identifying common principles. Public Integrity 13, 301-318. doi: 10.2753/PIN1099-9922130401

Vernon, M. E., and Clark, S. G. (2016). Addressing a persistent policy problem: the elk hunt in Grand Teton National Park, Wyoming. Soc. Nat. Resour. 29, 836-851. doi: 10.1080/08941920.2015.10 80337

Conflict of Interest: The authors declare that the research was conducted in the absence of any commercial or financial relationships that could be construed as a potential conflict of interest.

Publisher's Note: All claims expressed in this article are solely those of the authors and do not necessarily represent those of their affiliated organizations, or those of the publisher, the editors and the reviewers. Any product that may be evaluated in this article, or claim that may be made by its manufacturer, is not guaranteed or endorsed by the publisher.

Copyright (c) 2021 Pomeranz, Hare, Decker, Forstchen, Jacobson, Smith and Schiavone. This is an open-access article distributed under the terms of the Creative Commons Attribution License (CC BY). The use, distribution or reproduction in other forums is permitted, provided the original author(s) and the copyright owner(s) are credited and that the original publication in this journal is cited, in accordance with accepted academic practice. No use, distribution or reproduction is permitted which does not comply with these terms. 